\title{
Optimization of ultrasound extraction of Wolfberry Flavonoids and its antioxidant activities
}

\author{
Jianping Zhang, Yonghua Wu, Enqi Liu*, Shanglong Chen \\ Jiangsu Key Construction Laboratory of Food Resources Development and Quality Safe, Xuzhou \\ Institute of Technology, Xuzhou 221111, China \\ a915150123@qq.com, byonghuawu2006@163.com, 9leq@xzit.edu.cn, \\ 'longfeng821003@163.com
}

Keywords: Flavonoids, Ultrasound, Antioxidant

Abstract. The solidtosolvent ratio, ethanol concentration, extraction temperature and extraction time were investigated for extracting total flavonoids from wolfberry. The optimal conditions were found to be extracted at the ratio of material to solvent $1: 20(\mathrm{~g} / \mathrm{mL}), 60{ }^{\circ} \mathrm{C}$ for $40 \mathrm{~min}$ with $70 \%(\mathrm{v} / \mathrm{v})$ ethanol. The D101 macroporous resin was chosen to purify the flavonoids from the crude extracts, the ORAC value of purified flavonoids was enhanced $83.38 \%$ than that of the crude one.

\section{Introduction}

Wolfberry (Lycium barbarum) is one of the bestknown traditional Chinese herbal medicine. It has been widely used as healthy food for thousands of years in China[1]. The main active constituents of Wolfberry include polysaccharides, flavonoids and trace elements. Many researches showed that wolfberry fruits and its extracts possess pharmacological and physiological effects, e.g., brighten eyes, nourish the liver, nourish Yin and strengthen kidney, antioxidant, antifatigue, antiaging, lowering bloodglucose and serum lipids, immunity enhancement and anticancer[2].

Lots of previously published literatures about wolfberry were focus on polysaccharides, however, the papers about flavonoids were rare. Hence, the present work investigates the optimal parameters for extracting flavonoids from Wolfberry. Moreover, the crudes extracts were purified by macroporous resin and its antioxidant activities in vitro were measured by oxygen radical absorbance capacity (ORAC) assay.

\section{Materials and methods}

\section{Materials}

The Wolfberry were kindly provided by Ningxia Tang Ming Pharmaceutcal Co., Ltd., the herbs were ground with a DFY1000C omnipotent disintegrator (Wenling Dade machinery Co., Ltd., China) to get a relatively homogenous drug powder and then sieved through 100mesh screen. The Wolfberry powder was stored in a desiccator.

The standard of Rutin (>98\%) was purchased from Bei Na Chuang Lian Biotechnology Institute of Beijing. All other chemical agents were analytical grade.

\section{Extraction methods}

Ultrasoundassisted extraction (UAE) experiments were carried out in a DCTZ2000 multipurpose thermostatic ultrasonic extraction machine (Beijing Hongxianglong Biotechnology Co., Ltd., China). Briefly, about $50 \mathrm{~g}$ Wolfberry powder was extracted by using ethanol in a designed material to solvent ratio (1:5-1:30 $\mathrm{g} / \mathrm{mL})$, ethanol concentration $(50-100 \%, \mathrm{v} / \mathrm{v})$, extraction temperature $\left(30-80^{\circ} \mathrm{C}\right)$ and sonication time $(10-60$ min). After extraction, the mixtures were centrifuged in a centrifuge (L550, Xiangyi Instrument Co. Ltd., 
Changsha, China) at $2811 \times \mathrm{g}$ for $10 \mathrm{~min}$, and the supernatants were collected and put into a volumetric flask, adjusted to appropriate volume with corresponding solvent.

\section{Purification of wolfberry flavonoids by D101 macroporous resin}

As the good performance on purification of natural products, the macroporous adsorption resins are widely used in the recovery or separation of flavones and polyphenols. On the basis of preliminary experiments, the D101 macroporous resin was chosen for separating flavonoids from wolfberry extracts.

The crude flavonoids was extracted under the optimal conditions, after centrifuging, the supernatants were collected, and the remaining ethanol was removed by rotary evaporation, the protein was removed by Sevage reagent (nbutylalcohol:chloroform=1:5, v/v), the polysaccharides were eliminated by $95 \%$ ethanol. After the removal of protein and polysaccharides, the rest of extract was concentrated by reducing pressure and dried by vacuum freeze, finally, wolfberry flavonoids is obtained and stored in a $80^{\circ} \mathrm{C}$ freezer for further use.

Exactly $25 \mathrm{~g}$ of the pretreated D101 macroporous resin was added into a $1000 \mathrm{~mL}$ triangular flask, then $500 \mathrm{~mL}$ crude extracts of wolfberry was added. The flask was shaken on an oscillator $(160 \mathrm{r} / \mathrm{min})$ at $25{ }^{\circ} \mathrm{C}$ for $24 \mathrm{~h}$ to reach the adsorption equilibrium. After the adsorption equilibrium had been reached, the resins were washed twice using $500 \mathrm{ml}$ distilled water and then desorbed by $500 \mathrm{~mL} 95 \%$ (v/v) ethanol solution in a flask, which was shaken on an immersion oscillator (130 r/min) at $25{ }^{\circ} \mathrm{C}$ for $24 \mathrm{~h}$.

\section{Determination of total flavonoid content}

The total flavonoid content was determined by using the method reported by WANG [3] with minor modification. Briefly, $1 \mathrm{~mL}$ sample solution was put into a $25 \mathrm{~mL}$ volumetric flask and mix with $1 \mathrm{~mL} 5 \%$ $\mathrm{NaNO}_{2}$, after6minstanding, added $1 \mathrm{~mL} \mathrm{10 \%} \mathrm{Al}\left(\mathrm{NO}_{3}\right)_{3}$ and stand for $6 \mathrm{~min}$, then $10 \mathrm{~mL} \mathrm{4 \%} \mathrm{NaOH}$ was added, at last, the mixture was adjusted to $25 \mathrm{~mL}$ with $70 \%$ ethanol, stir and let stand for 30 minutes. The absorbance was measured at $510 \mathrm{~nm}$ by ultravioletvisible spectrophotometer (TU1810, Beijing Purkinje General Instrument Co., Ltd.), and the $70 \%$ ethanol was employed as a blank control. Rutin was adopted as a standard, the regression equation was as flowed, $y=0.0798 x+0.0003\left(R^{2}=0.9989\right)$, and the total flavonoid contents of extracts were expressed as rutin equivalents. All measures were performed in triplicate.

\section{Determination of oxygen radical absorbance capacity}

The radicalscavenging capacity was determinedby the ORAC assayusing fluorescein(FL)as the fluorescent indicator in according to Dávalos [4]. Briefly, the reaction was carried out at $37^{\circ} \mathrm{C}$ in $75 \mathrm{mM}$ phosphate buffer (pH 7.40). 20 $\mu$ Lof antioxidant (trolox or extracts) and $20 \mu$ Lof 10nM FLwere putin the well of the black 96well microplates, and then the microplate was incubated at $37^{\circ} \mathrm{C}$ for $15 \mathrm{~min}$ before $160 \mu \mathrm{L}$ AAPH solutions $(0.10 \mathrm{M})$ was addedrapidly to each well as peroxyl generator to trigger reaction. The microplate reader from BioTek Instruments was programmed to record the fluorescence reading atexcitation of $485 \mathrm{~nm}$ and emission of $535 \mathrm{~nm}$ at $1 \mathrm{~min}$ interval for 60 minusing software Gen $5^{\mathrm{TM}}$. And phosphate buffer was used as blank control, and the standard trolox at different concentrations $(0,6.25,12.50,25,50$ and $100 \mu \mathrm{M})$ were used to construct a calibrator. All the tests were performedin triplicate.

The regression equation between the net $\mathrm{AUC}$ and the antioxidant concentration was calculated. Theregression was $\mathrm{y}=93221 \mathrm{x}+8124810\left(\mathrm{R}^{2}=0.986\right)$. The final ORAC values for extracts were expressed as trolox equivalent (TE).

\section{Results and discussion}

\section{Effects of material to solvent ratio}

Generally, the yield of extracts will improveas the increase of solvent volume. Extractions were carried out at different material to solvent ratio $(1: 5-1: 30, \mathrm{~g} / \mathrm{mL})$ while the other parameterswere set as follows: at $50{ }^{\circ} \mathrm{C}$ 
with $60 \%$ ethanolfor $20 \mathrm{~min}$. The effects of different material to solvent ratioon flavonoids yieldwas shown in Fig. 1, the flavonoids yield enhanced with the increase of material to solvent ratio. Before $1: 20 \mathrm{~g} / \mathrm{mL}$, the yield of flavonoids increase rapidly, however, it was become very slowly as the ratio was abovethat. Considered the concentrate and to lowerthe costs, the value of $1: 20 \mathrm{~g} / \mathrm{mL}$ was employed as the optimal ratio of material to solvent for the experiments.

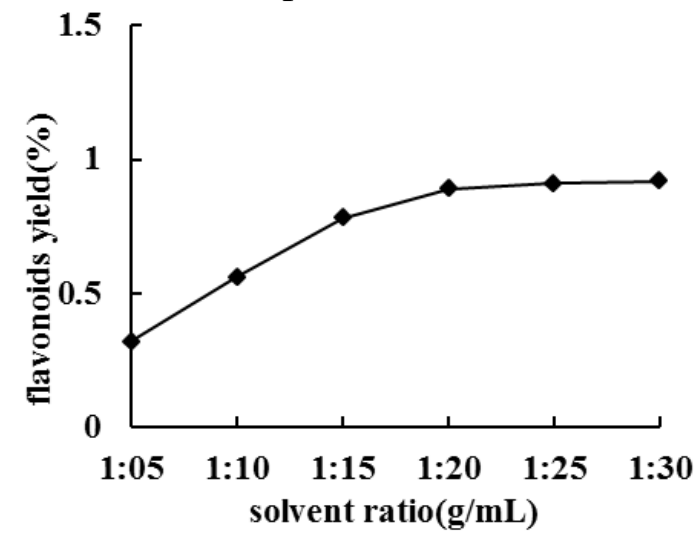

Fig. 1 Effects of material to solvent ratio on flavonoids yield.

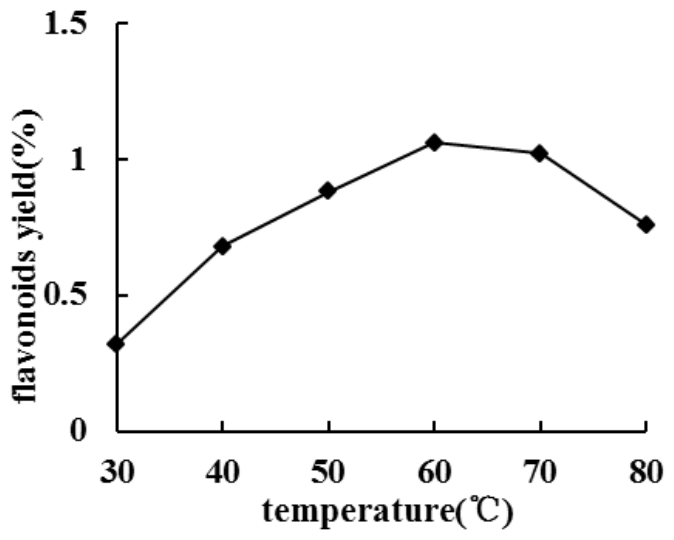

Fig.3 Effects of temperature on flavonoids yield.

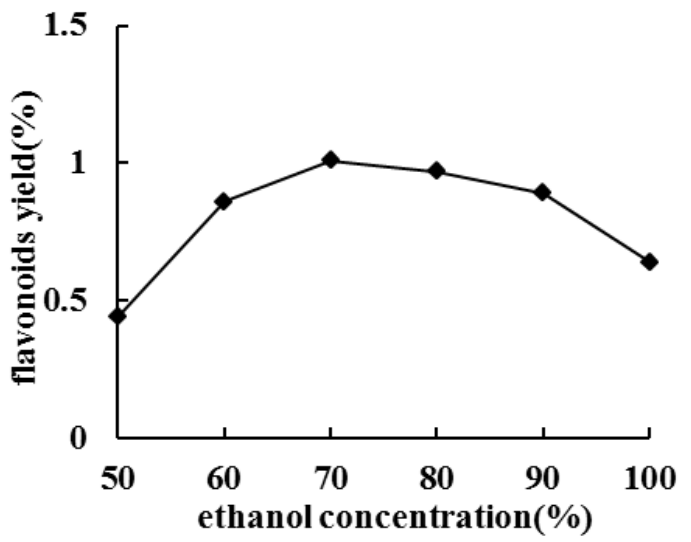

Fig. 2 Effects of ethanol concentration on flavonoids yield.

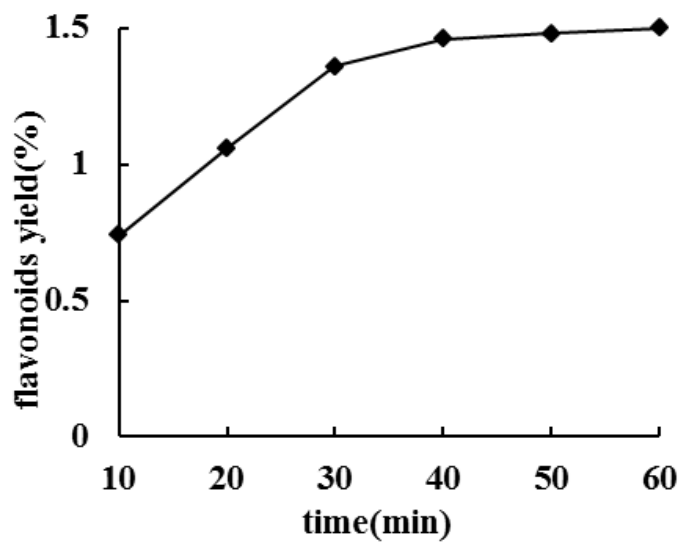

Fig.4 Effects of time on flavonoids yield.

\section{Effects of ethanol concentration}

$50 \mathrm{~g}$ herbs powder was placed into the extracted pool for extracting with $1000 \mathrm{~mL}$ ethanol at $50{ }^{\circ} \mathrm{C}$ for 20 min. The concentration of ethanol varied from 50\% to 100\%. As seen in Fig.2, the ethanol concentration could great influence the flavonoids yield, it increased with the increase of ethanol concentration when the ethanol volume percentage in the solvent was lower than $70 \%(\mathrm{v} / \mathrm{v})$, but the yields were decreased when the cthanol concentration was higher than $70 \%$. Thus, the $70 \%$ was considered as the best ethanol concentration for this process.

\section{Effects of extraction temperature}

The effects of different temperature $\left(30-80{ }^{\circ} \mathrm{C}\right)$ on the yield of flavonoids were carried out with $1000 \mathrm{~mL}$ $70 \%$ ethanol for 20 min.As shown in Fig.3, the yield of flavonoids enhancedwith the increase of temperature from 30 to $60{ }^{\circ} \mathrm{C}$, however, the yields were decreased when the temperature was higher than $60{ }^{\circ} \mathrm{C}$. The results indicatedthat increasetemperature properlymay improve the flavonoids yield as higher temperature may break down the plant cell wallsmore thoroughly, but on the other hand, higher temperature may resolvetheflavonoids, leading todecreasethe recovery. According to the results, $60^{\circ} \mathrm{C}$ was chosen for the experiments. 


\section{Effects of extraction time}

Use In general, extraction time play a vital role in enhancing the extraction efficiency of phytochemicals. The yield of wolfberry flavonoids extracted over different time from 10 to $60 \mathrm{~min}$ was seen in Fig.4, when the other factors were designed as follows: ratio of material to solvent 1:20, ethanol concentration $70 \%$, ultrasonic temperature $60{ }^{\circ} \mathrm{C}$. The results indicated that the yield of flavonoids increased greatly with the duration of extraction time from 10 to $40 \mathrm{~min}$; however, the yield enhanced slowly when the action time longer than $40 \mathrm{~min}$. Consider to reduce energy consumption and save time, $40 \mathrm{~min}$ was chosen as the optimal time for the trials.

\section{The ORAC value of wolfberry flavones}

The wolfberry flavonoids were extracted by above process (ratio of material to solvent 1:20, ethanol concentration $70 \%$, ultrasonic temperature $60{ }^{\circ} \mathrm{C}$, extraction time $40 \mathrm{~min}$ ), and then purified by D101 macroporous resin. The antioxidant activities of crude extracts and the purified flavonoids were measured by ORAC assay. The results were shown in Table 1, the ORAC value of purified flavonoids was nearly twice as that of the crude extracts, reached to $70.60 \mu \mathrm{mol} \mathrm{TE} / \mathrm{L}$. The results indicated that the $60 \%$ ethanol extracts from wolfberry possess good antioxidant capacity; moreover, the activity was enhanced sharply by using D101 marcoporous resin for purification.

Table 1. The ORAC value of flavonoids

\begin{tabular}{ccc}
\hline Fractions & $\begin{array}{c}\text { Concentration } \\
(\mathrm{mg} / \mathrm{mL})\end{array}$ & $\begin{array}{c}\text { ORAC value } \\
(\mu \mathrm{mol} \text { TE/L })\end{array}$ \\
\hline Crude extracts & 5 & 38.45 \\
Purified flavonoids & 5 & 70.60 \\
\hline
\end{tabular}

\section{Conclusion}

The ultrasoundassistant extraction process was developed for extracting flavonoids from wolfberry. The optimal parameters were found as solvent ratio $1: 20(\mathrm{~g} / \mathrm{mL})$ with $70 \%(\mathrm{v} / \mathrm{v})$ ethanol at $60^{\circ} \mathrm{C}$ for $40 \mathrm{~min}$. The yield of flavonoids reached $1.48 \%$ under these conditions, and the D101 macroporous resin was proven as an effective and efficient purification technique, which could greatly improve the antioxidant activity.

\section{Acknowledgements}

This work was financially supported by the open project program of Jiangsu key laboratory of food resource development and quality safety, Xuzhou Institute of Technology (No.SPKF201407)and the scientific research projectsof Xuzhou Institute of Technology (No.XKY2013324).

\section{References}

[1] ZHANG J., JIA S.Y., LIU Y., WU S. H. RAN J. Y.. Optimization of enzymeassisted extraction of the Lycium barbarum polysaccharides using response surface methodology. Carbohydrate Polymers, 86:10891092. (2011)

[2] JIN M.L., HUANG Q.H., ZHAO K., SHANG P.. Biological activities and potential health benefit effects of polysaccharides isolated from Lycium barbarum L.. International Journal of Biological Macromolecules, 54:1623. (2013)

[3] WANG Y. M., CHEN H. W., TIAN C., XIE M. H.. Study on Extraction Method of Loquat Leaves Flavonoids. Journal of Xuzhou Institue of Technology, 29(2):3638. (2014) 
[4] Dávalos, A., GómezCordovés, C., Bartolomé, B. Extending applicability of the oxygen radical absorbance capacity (ORACfluorescein) assay. Journal of Agricultural and Food Chemistry, 52(1), 4854.(2004) 